Volume (3) No. (4) 2020

التعليم في زمن كورونا: (COVID-19) تجسير الفجوة بين "البيت" و"المدرسة"

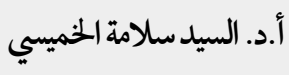

http://dx.doi.org/10.29009/ijres.3.4.1 


\section{التعليم في زمن كورونا (COVID-19): تجسير الفجوة بين "البيت" و"المدرسة"}

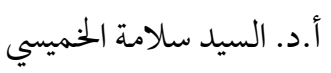

$$
\text { أستاذ أصول التربية، جامعة دمياط، مصر }
$$

selkhamisy@yahoo.com

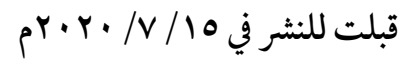

$$
\begin{aligned}
& \text { قدمت للنشر في } 1 \text { / / •r.r. }
\end{aligned}
$$

مستخلص: إن هذه الورقة نظرية تحليلية استشر افية، مسعاها تحليل الظروف و الوقائع المستجدة في العالر بعد ظهور جائحة كورونا، وما أدت إليه من زلزلة النظم المجتمعية المستقرة، وعلى رأسها نظم التعليم الرسمية في ختتلف دول العالم في شتى أرجاء المعمورة. وتعني هذه الورقة تحديدًا بها الخصائص التي تجعل الرهان عليه واردًا، وخاصة حين يعنى المسئولون عن التعليم وغيرهم من الرسميين وغير الرسميين بتجسير الفجوة بين الطرفين الأصيل (المدرسة) و البديل (البيت). ولكي تتحقق هذه الشر اكة لتعويض التلاميذ عن حرمانهم من مدارسهم، فإن لذلك متطلبات لابد من توفيرها والوفاء بها، وهو ما تعني به هذه الورقة عبر محاورها الأربعة. الكلمات الدلالية: جائحة كورونا، كوفيد 9 (، زمن كورونا، التجسير، نظم التعليم، التعليم الالكتروني. 


\title{
Education in Corona (COVID-19) Time: Bridging The Gap Between Home and School
}

\author{
Prof. Dr. Al-Sayed Salama El-Khamisy \\ Professor of Foundations of Education, Damietta University, Egypt \\ selkhamisy@yahoo.com
}

Received in 1st May 2020

Accepted in 15th Jul 2020

\begin{abstract}
This paper is a prospective Analytic theory, aims to analyzing the latest conditions and events taking place all over the world after Coronavirus Pandemic and its consequences that convulsed the steady societal systems; at the top of them all are formal educational systems in different countries all around the world. This paper is specifically concerned with the matter of opting to E-Learning/Distance Learning by the contemporary educational systems- including Arab ones- in Corona Pandemic Time. This educational adopted strategy- as a potential alternative after study being suspended and schools being closed- made "Home" as a candidate alternative educational/learning medium instead of the classrooms and schools. This candidate educational and instructional medium within distance learning paradigm faces- in Arab environment, generally, and Egyptian environment, in particular- a number of challenges. However, as potential educational option, it has some opportunities, as well as some characteristics that make petting on it conceivable; particularly, when people in charge and interested-formal and informal- concern about bridging the gap between the two parties; the original (school) and alternative (Home). In order to achieve this partnership for compensating students for depriving them from school, there are requirements to be met; which is the aim of this paper through its four pivots.
\end{abstract}

Key Words: Corona Pandemic, COVID 19, Bridging, E-Learning, Educational systems. 
مقدمة - مق

فقد قلبت جائحة كورونا (COVID-19) موازين العاله رأسًا علن عقب. وشاعت العبارة

$$
\text { الشهيرة التي تعبر عن ذلك عبر العالم وهي "تغير كل شيء في زمن الجائحة...!!؟؟" }
$$

اهتزت أعتى النظم الاقتصادية وأكثرها استقرارًا أمام الجائحة. وتعرضت النظم

السياسية وأشكال الحكم وأكثرها ثباتًا ورسوخًا لأزمات ليس ها بها سابق عهد. وتأثرت التجارة عبر العالم وبين أركان المعمورة بها لم تشهده من قبل. وتوترت علاقات بين كيانات اقتصادية وسياسية كبرىن بمستويات توتر لمتعاصرها من قبل (الو لايات المتحدة والصين على لئ سبيل المثال). و وانشخل الناس في خختلف أنحاء المعمورة - بفعل ثورة الاتصالات، وعولمة كل شيء -بالجائحة وتداعياتها، وردود الأفعال بشأنها، وتباين التوقعات بشأن سيناريوهاتها المستقبلية. واهتزت منظومات القيم في مختلف المجتمعات المعاصرة، وفي داخل كل مجتمع، وحتن علن مستوي الأفراد. وتغير هرم الأولويات لدى الدول، ولدى المجتمعات، ولدي الجلماعات، بل.... ولدي الأفراد. واحتلت دول وكيانات ومنظلات عالمية دائرة الضوء وبؤرة اهتحام الوعي الكوني لعلاقتها الأوثق بالجائحة (كالصين التي بدأ فيها الفيروس، ومنظمة الصحة العالمية WHO كأكبر منظمة عالمية مسئولة عن صحة سكان الكو كب وما يهددها من

وفي عصر العولمة وثورة الاتصال والثورة الصناعية الرابعة، يستحيل أن تكون منطقتنا العربية استثناء مما أحدثته كورونامن تغيرات. بل ربما تكون منطقتنا العربية أكثر من غيرها تأثرًا بالتغيير الذي أحدثثه الجائحة، لعوامل ومتغيرات يختص بها عالمنا العربي - تاريخيًا وجغرافيًا وديمو جر افيًا وثقافيًا وبيئًا - لا تتوفر في سو اه من أقاليم العالم ومناطقه الأخرىن. و إذا كان كل شيء قد تغير في زمن كورونا، فإن (التعليم) ليس استثناءٌ من التغير أو التغيير، بل ربحا قد فاق التعليم غيره من الأنشطة والقطاعات الأخرى لأنه أكثرها ارتباطًا بالبشر 
ومستقبلهم. فالتعليم، ووفقًا لمفاهيم التنمية المستدامة، وصناعة المستقبل، هو الأكثر انخراطًا

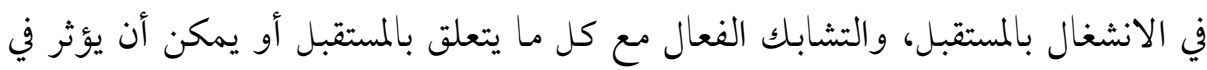

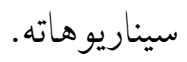

فحينا فاجأت هذه الجائحة العالم في مارس 2020، وبدأت تفاعلاتها وتداعياتها تعبر الحدود وتجتاح الدول والمجتمعات، اتخذت 138 دولة قرارات بإغلاق تام أو جزئي للمدارس والمجموعات، وهو ما يعني أن 1.38 مليار تلميذ وطالب عبر العالر تأثروا سلبيًا. أي أنه بين كل

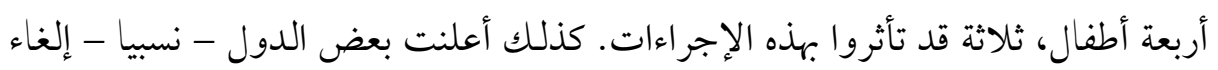

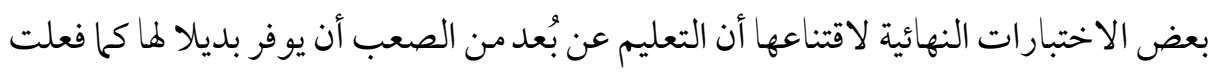
فرنسا. ومن هنا جاءت فكرة هذه الورقة، وتبلورت إشكاليتها منهجيا. 1 الإشكالية وأسئلتها المثارة. ولما كان من أهم انعكاسات الجائحة علن التعليم اضطرار الدول إلى تعليق الدراسة النظامية والتعليم المدرسي الرسمي Formal Schooling ضمن الاجراءات الاحترازية التي

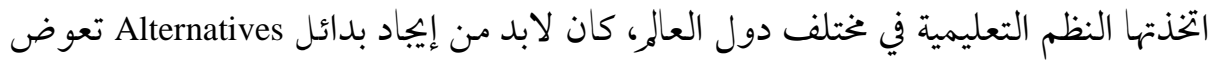
التلاميذ و الطلاب عن حرمانهم من التعليم المدرسي. وقد استثارت هذه الوضعية المستجدة مع كوفيد -19المستجد (19-COVID)، العقل التربوي عبر العالر، فاستحضرت الذاكرة التربوية

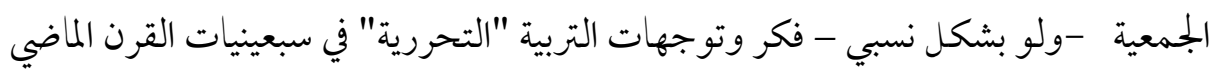
ل "إيفان إيلتش" و " وإيفرت ريمر" و"باولو فريري"، وخاصة حركة اللامدرسية Deschooling Society القرن الماضي.

http://dx.doi.org/10.29009/ijres.3.4.1 
واللامدرسية -بتعبير آخر في الانجليزية (Unschooling -هي شكل من أشكال التعليم يعتمد فيها التعلم على اهتمامات وميول ورغبات وأهداف المتعلم. وتنطابق اللامدرسية مع أشكال التعليم المنزلي الأخرى في أن النظام التعليمي للطالب ليس موجها من قبل معلمين أو مناهج دراسية، ومع ذلك فإن للطالب اللامدرسي حرية الانتفاع من المعلمين أو الاطلاع علن الكتب الدراسية، فهو المسئول والمتحكم الأول في الطريقة التي يتعلم بها، وهو من يختار إجابات أسئلته التي تحدد خياراته، لماذا، وماذا، وكيف، وأين،

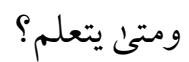

فقد طرحت أزمة كورونا علن التعليم بمختصيه Authorized ومتخصصيه Specialists البحث عن إجابات جديدة للأسئلة الكبرى القديمة التي يدور حو لها التعليم بفلسفته، ومحتو اه، وأساليبه، وطر ائقه، وأزمنته، وأمكنته مثل:

Knowing Why? , Knowing What? , Knowing How? , Knowing Where?, Knowing When?

فقد تسببت جائحة فيروس كورونا (COVID-19) في انقطاع أكثر من 1.6 مليار طفل وشاب عن التعليم في 161 بلدًا، أي ما يقرب من 80\% من الطلاب الملتحقين بالمدارس حول العالم. و جاء ذلك بالفعل في وقت يعاني فيه العالمرن أزمات تعليمية حقيقية حيث يظهر مؤشر البنك الدولي عن "فقر التعلم" الذي وصلت نسبته في البلدان منخفضة ومتوسطة الدخل قبل تفشي الفيروس إلى 53\%. 


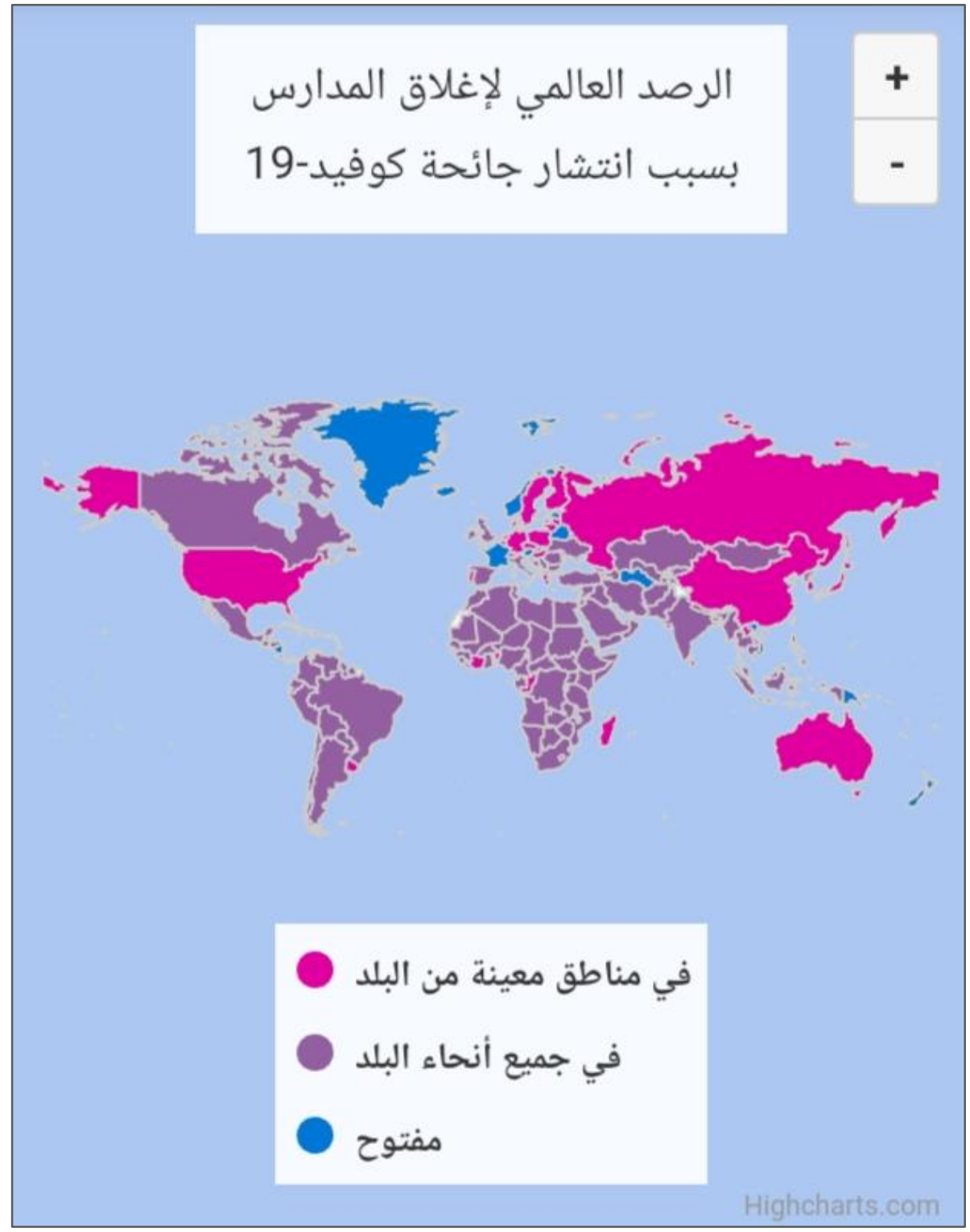

http://dx.doi.org/10.29009/ijres.3.4.1 


\section{$14 / 07 / 2020$}
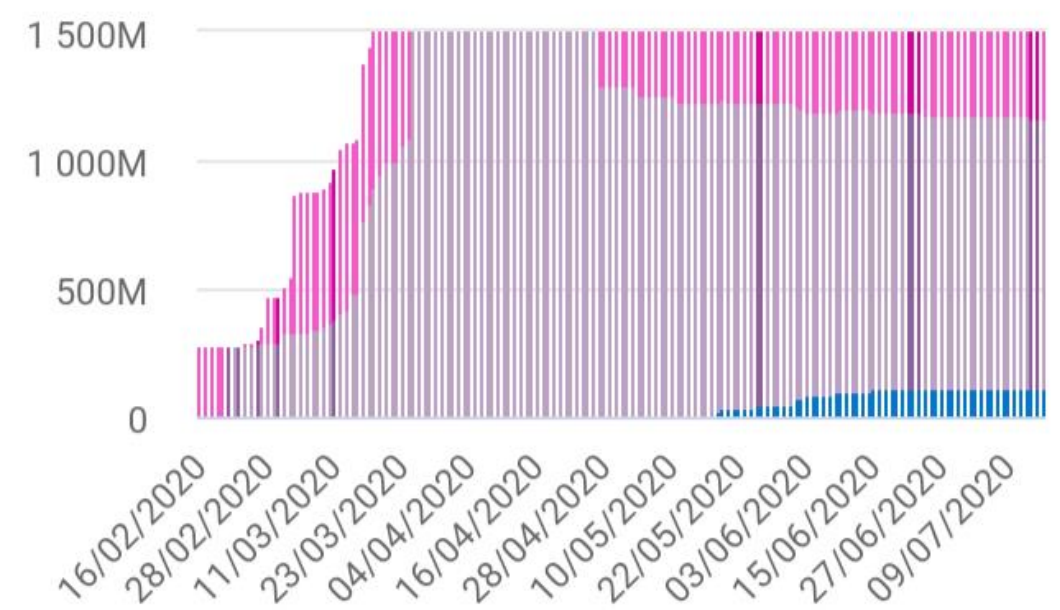

\section{1,058,897,779 الدارسون المتأثرون 60.5\% إجمالي عدد الدارسين المسجّلين 109 إغلاق في جميع أنحاء البلد}

ولما كانت جل إجابات الأسئلة السابقة قد تغيرت -إلى حد ما - في ظل مستجدات

الجائحة، فقد أصبح لزامًا على الأنظمة التعليمية البحث عن خيارات تعليمية تكون متحررة من قيود وضو ابط التو اجد الفيزيقي للمتعلمين بمدارسهم من خلال التعليم المدرسي الرسمي.

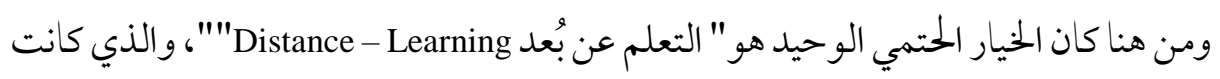
أقرب أشكاله وأكثرها إتاحة هو "التعليم بالبيت Education at Home" أو "التعليم المنزلي Home Education " أو Home Schooling"" و و إن كانت الأخيرة تختلف نسبيًا عن سابقاتها. هذا يعني، أن من أهم تجليات أزمة كورونا تعليميًا - علن مستوي العاله - تصدر "البيت" Home للمشهد كخيار حتمي ليصبح وسيطًا تعليميًا شبه رسمي، وإن اختلفت 
تطبيقات هذا الخيار من دولة إلي أخرىن، ومن نظام تعليمي إلى آخر، ومن منطقة لأخرى داخل البلد الو احد، بل ومن بيت لآخر لتلاميذ المدرسة الواحدة. ولكن، وفي كل الأحوال، أصبحنا أمام " شر اكة تعليمية Educational Partnership "بين "مدرسة" التلميذ و"بيته". ومن هنا يمكن بلورة "إشكالية "هذه الورقة منهجيا في هذا السؤ ال المركب الرئيس:

111 كيف يمكن تعظيم فرص الشر اكة التعليمية بين المدرسة والبيت، لتجنب نقاط الضعف والتهديدات، والإفادة من الايجابيات والفرص في البيئة التعليمية للمتعلم في هذه المرحلة

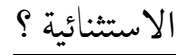
ويتفرع من هذا السؤال الرئيس الأسئلة الفرعية الأربعة الآتية:

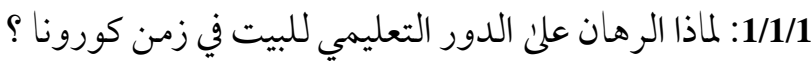
1/1/2 ما أهم التحديات التي تواجه الدور التربوي/ التعليمي للبيت العربي؟

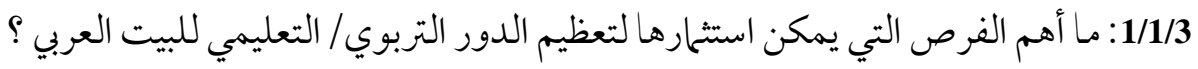
1/1/4: ما أهم متطلبات تحقيق شر اكة تعليمية فاعلة بين المدرسة والبيت في زمن كورونا ؟ r-منهجية الورقة وحدودها في الإجابة عن الأسئلة.

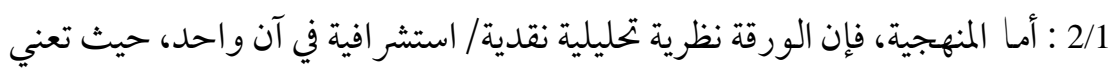
بالوصف التحليلي للمتاح من البيانات و الأدبيات، في ضوء فلسفة الكاتب التربوية ولمدية والمرجعيات النظرية و المفاهيمية مثل "إدارة الأزمات التعليمية" و"التعليم عن بُعد" و "التعلم الإلكتروني"

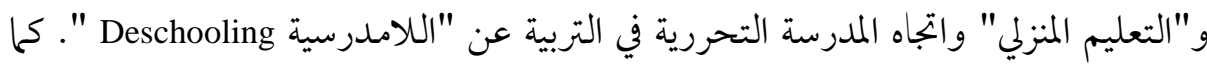
تعني الورقة بمحاولة تلمس آفاق الشر اكة بين المدرسة والبيت بعد أزمة كورونا.

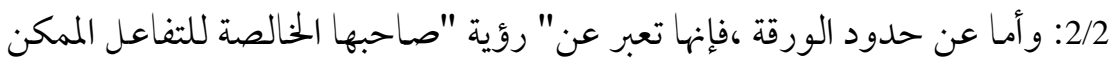
مع انعكاسات جائحة كورونا علي التعليم المعاصر، وكيف يمكن تو جيه هذا التفاعل لتعظيم 
المتاح والممكن من الشراكة بين المدرسة والبيت للحد من الأضرار الناتجة علن تعليم التلاميذ والطلاب جراء جائحة كورونا.

ب- لماذا الرهان على الدور التربوي/ التعليمي للبيت في زمن الجائحة؟

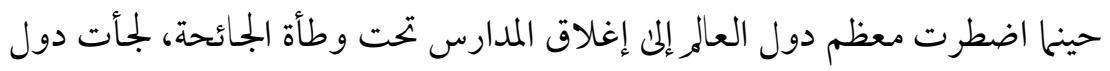

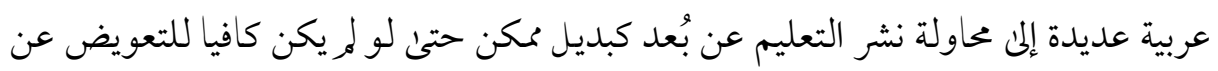

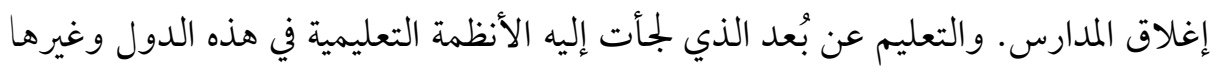
يعني، أن تعليم وتعلم التلاميذ انتقل - مكانيا - من المدرسة إلى البيت، وتحول -أدائيًا -من

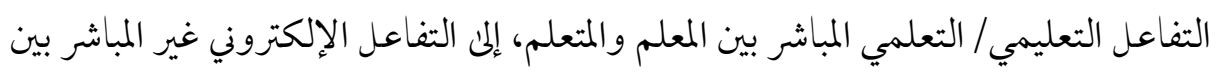

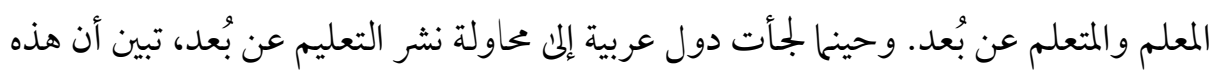

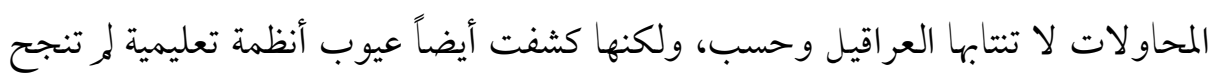

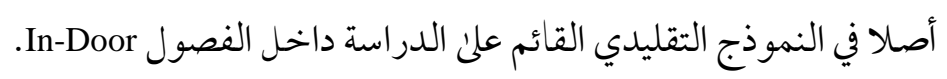

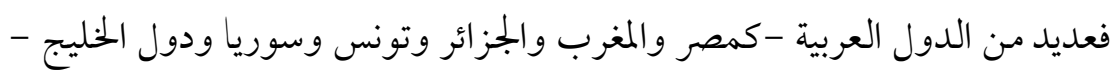
استنجدت بالتعليم عن بُعد لمحاولة إنقاذ الموسم الدراسي، معلنة عن مواقع خاصة تنيح

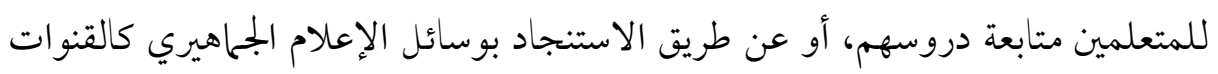
التليفزيونية والإذاعات الحكومية. وبالطبع حين يتلقى المتعلم التعليم عن بُعد، فإنه يتلقاه غالبًا

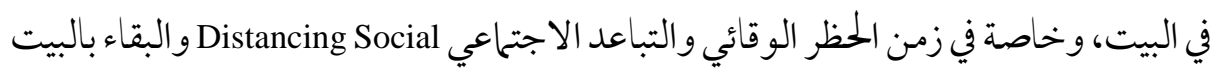
Stay Home وغيره من الدعوات التي طغت علن المشهد في زمن الجائحة.

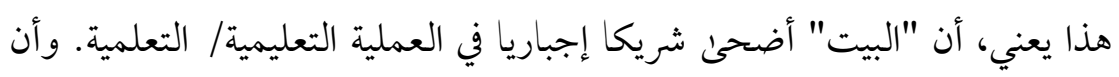

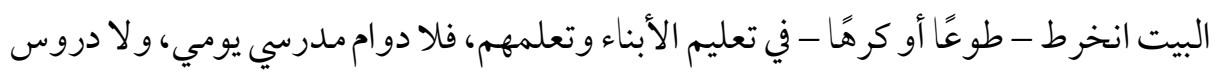
خصوصية، و لا تفاعل مباشر بين المتعلمين و المعلمين، فبديل ذلك كله تعليًا إلكترونيًا أو إذاعيًا

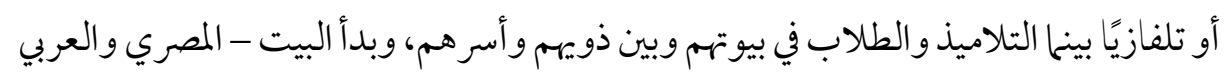


وغيره - يكتسب بعدًا مستحدثًا و قصديًا في مناخه إلى جانب أبعاده الاجتماعية والتربوية وهو البعد "التعليمي" وكأنما استجد مناخ جديد أقرب إلى التعليم المنزلي Home Schooling، و كأنما دخل العالر طو اعية أو إجبارًا في البدائل التي طرحتها منذ نصف قرن فلسفة "اللامدرسية" عند إيلتش Illich وريمر Remer وفريري Frere. فقد جاءت جائحة كورونا لتجبر النظم التعليمية في البلدان العربية على انتقال مفاجئ نحو التعليم عن بعد. وحاولت الوزارات المعنية-كالتربية والتعليم، والتعليم العالي والاتصالات والإعلام - تسهيل العملية باستحداث منصات للتعليم الإلكتروني لإيصال الخدمة التعليمية للمتعلمين في أماكن إقامتهم عوضًا عن انسحاب المدرسة -الاضطراري من الفعل التعليمي المباشر ـ ولما نتج عن لجوء نظم التعليم العربية للتعليم عن بُعد ظهور مشكلة غياب "التفاعلية" في العملية التعليمية في ظل هذا التحول، لجأت هذه النظم إلى أساليب وآليات مستحدثة تدعم التعليم في البيت وتقلل من حدة غياب التفاعلية المباشرة بين المعلمين والمتعلمين.

فقد اهتمت وزارة التعليم المصرية - على سبيل المثال -بمشكلة التفاعلية وأطلقت لذلك موقع "إدمودو Edmodo " الذي يتيح التو اصل بين التلاميذ والمعلمين حول الدروس والمو اد التعليمية. وخططت وزارة التربية والتعليم المصرية لاستفادة Yr مليون تلميذ وطالب من الموقع، لكن يبقى الحكم علي مدىن نجاح الموقع في حل مشكلة التفاعل سابق لأوانه. وفي هذا الإطار -جهود النظم التعليمية لمواجهة مشكلة التفاعل -يأتي الاتفاق الذي أبرمته وزارة التعليم المغربية وشركات الانترنت لأجل تمكين التلاميذ من الدخول المجاني إلى المنصات التعليمية، بعد أن سبقتها مصر في ذلك، وقد أعلنت وزارة التعليم المغربية أن عدد مستخدمي البوابة الوطنية الخاصة بالتعليم عن بعد وصل إلى .7 ألف يوميًا وأن عدد المواد الرقمية المصورة فيها بلغ م. . . م في مطلع إبريل الماضي. 
واستخلاصًا مما سبق، يمكن الإقرار بأن الظروف القهرية المفاجئة للجائحة، قادت إلى أنى

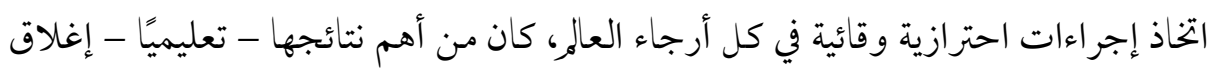
المدارس بمختلف مستوياتها ومر احلها وأشكاها. فقد جاءت الجائحة لتزلزل النظم التعليمية القائمة، كما زلزلت غيرها من النظم المجتمعية الأخرىن.

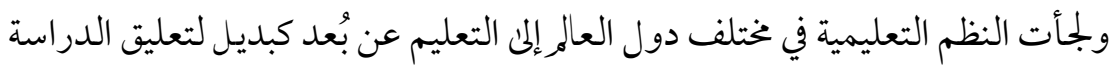
بالمدارس. وأدي انتشار التعليم عن بعد من خلال التعلم الإلكتروني إلى تعليم وتعلم التلاميذ

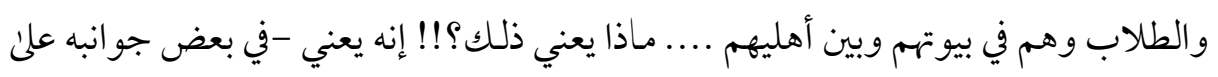
الأقل - أن البيت أضحي شريخًا في تعليم وتعلم أبنائه، حيث ينخرط في في عملية تعليم وتعلم

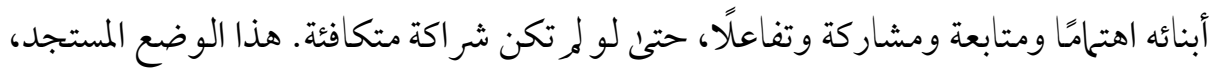

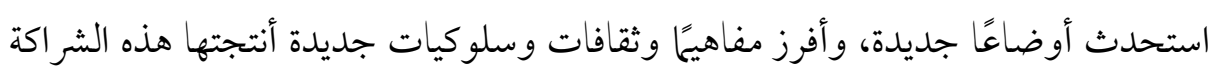

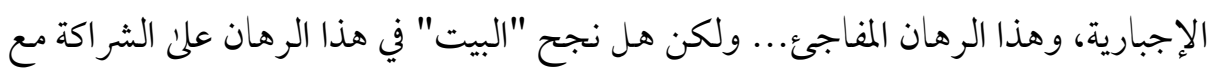

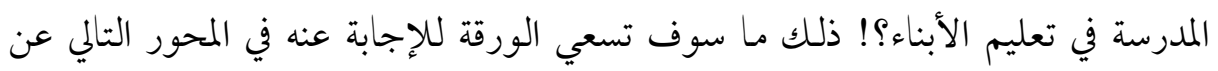
(تحديات) الدور التربوي/ التعليمي للبيت.

ع-أهم التحديات التي تواجه الدور التربوي/ التعليمي للبيت العربي.

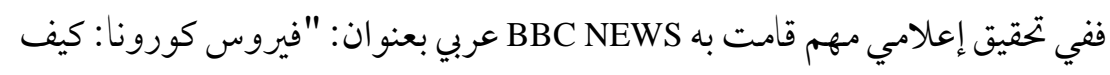

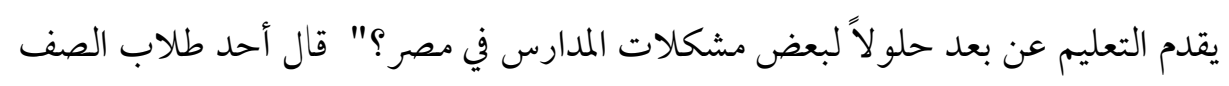
الأول الثانوي في مدرسة حكومية مصرية أثناء التحدث للقناة عن التجربة الجديدة في التعلم

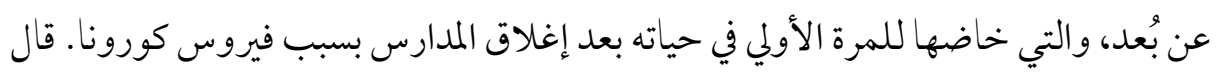

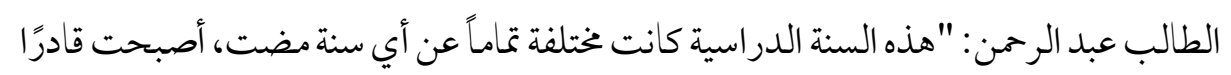

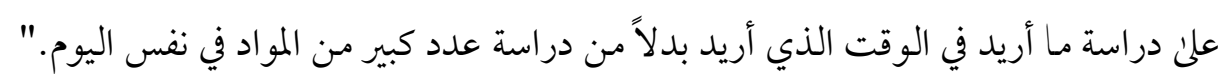


وأضاف عبد الرحمن ":كان عامًا دراسيًا تمكنت خلاله من التركيز لغياب عوامل التشتيت بسبب

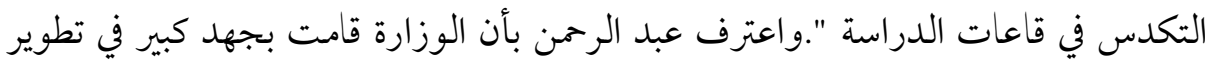
منصات التعليم والاختبارات في وقت قياسي لاستكمال العام الدراسي.

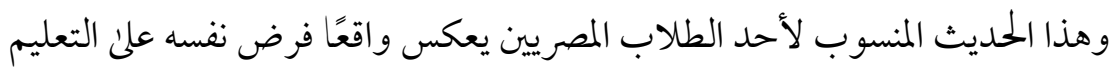

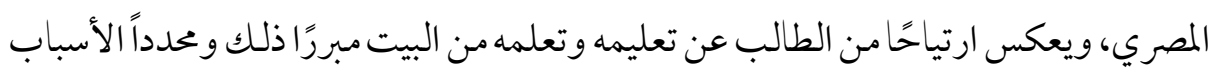
المتعلقة بازدحام الفصول المدرسية، والتشتت، وغياب حرية الاختيار لوقت ومادة التعليم

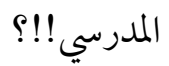
أما عن عيوب التعليم الإلكتروني عن بُعد في البيت، فيرئ أحد المعلمين المصريين من

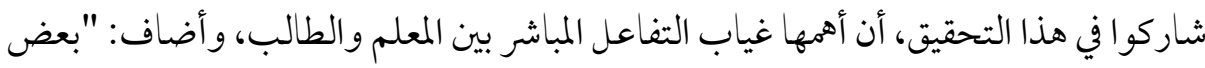

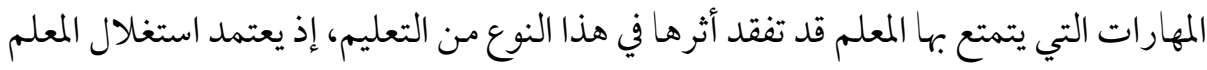
لها علن الوجود الحقيقي في قاعات الدراسة." وأضاف آخر أن التعليم عن بُعد، ولأنه مستجد و اللجوء إليه كان مفاجئًا واضطر اريًا،

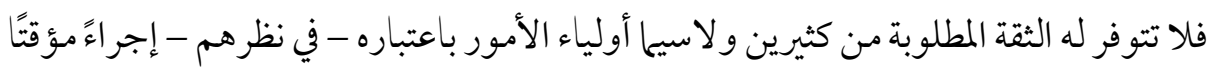
في ظل توقعهم بالعودة إلى المدارس بعد حين.

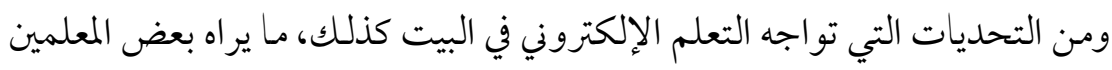

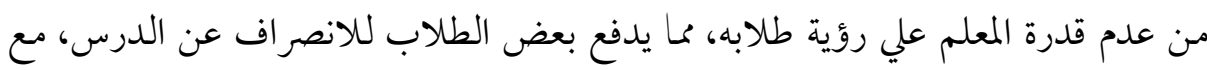

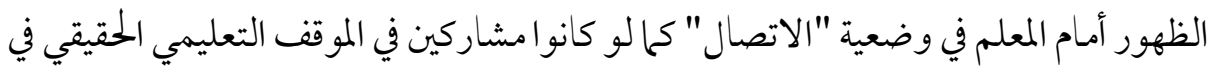

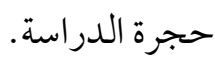

وكذلك يضاف إلى التحديات التي تواجه الدور التربوي/ التعليمي للبيت من خلال

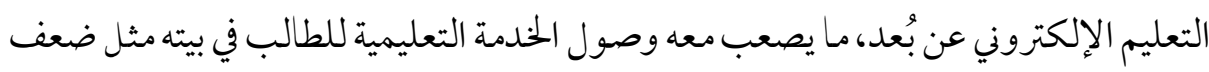
البنية التحتية التكنولوجية في المدارس والمنازل علن حد سواء مثل بهل الإنترنت والأجهزة http://dx.doi.org/10.29009/ijres.3.4.1 
المستخدمة في الاتصال لدئ أغلب المصريين، والتدريب علن هذا النوع من التعليم لدئ الطلاب والمعلمين.

ولا يقتصر هذا التحدي التكنولوجي والرقمي علن دولة عربية دون أخرىن، حيث يعبر

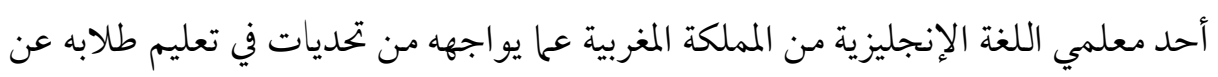

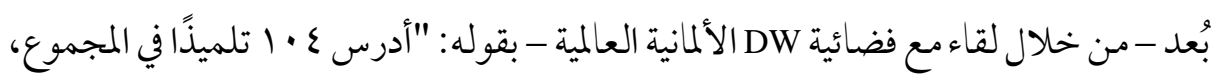
ووضعت برنابجًا للتو اصل معهم عبر واتساب Whats App، حيث أطلب منهم إنجاز التمارين

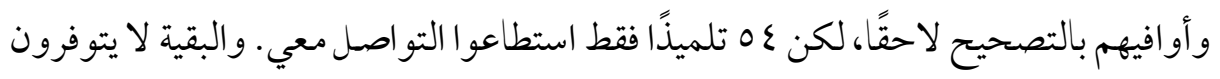

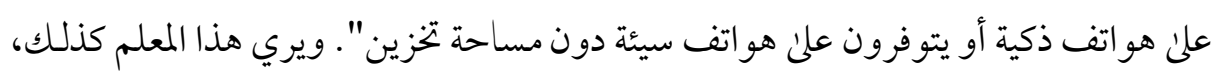

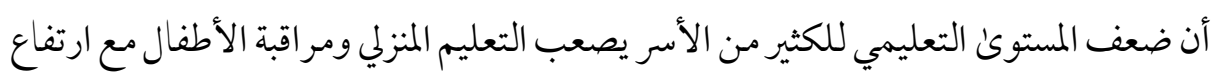
نسبة الأمية، وهذا تحد آخر.

وثمة تحد آخر يواجه هذا النوع من التعليم، ومن ثم يقلل من أهمية الدور

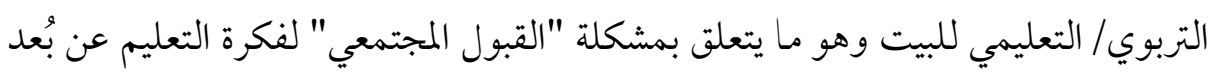

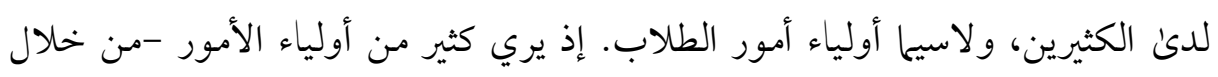

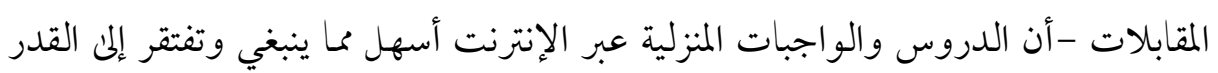

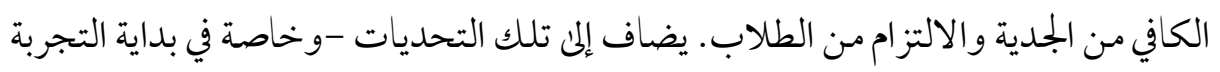

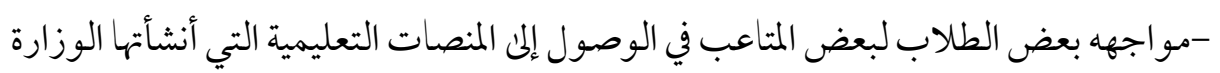

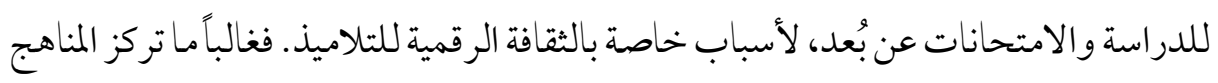
التقليدية علن برامج بسيطة مثل Office مقارنة مع مناهج دول متقدمة تتيح للتلاميذ دروسا

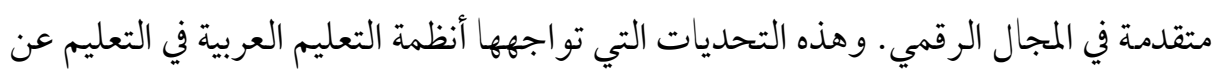

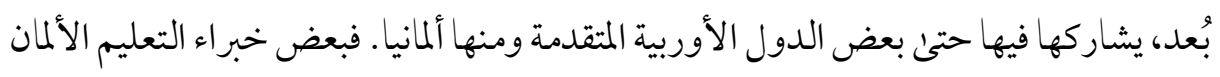

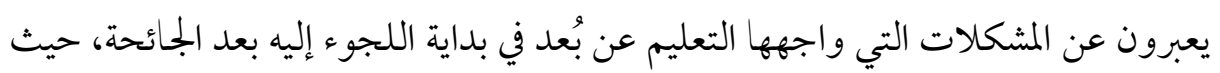


يرون أن ألمانيا من أسوأ الدول الأوربية في بجال التعليم الرقمي ويفسرون هذه الوضعية باللجوء إلى التعليم عن بُعد دون استعدادات مبكرة للتعليم الرقمي. فشبكة الانترنت في ألمانيا-وفقًا لهم - ضعيفة أو بطيئة في العديد من المناطق، كما أن أغلب المعلمين غير مدربين علن تقنيات التعليم

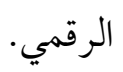
ومن التحديات المتعلقة بالفوارق الطبقية وانعدام تكافؤ الفرص بين التلاميذ في التعليم عن بُعد ومشاركة البيت في هذا الدور، أن كثيرا من التلاميذ، وفضلا عن عدم امتلاكهم

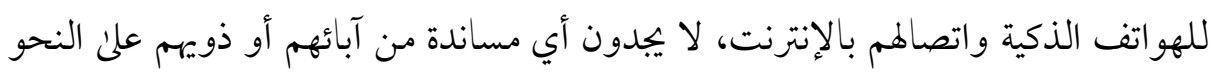

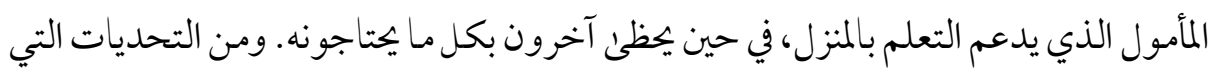

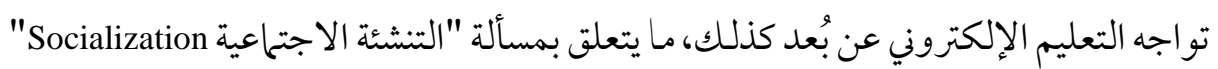

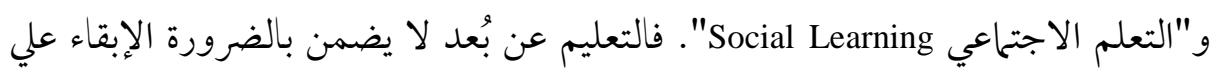

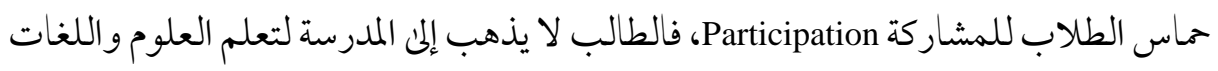
والرياضيات فحسب، ولكنه يذهب كذلك ليقيم علاقات اجتماعية ويتعامل مع أقرانه

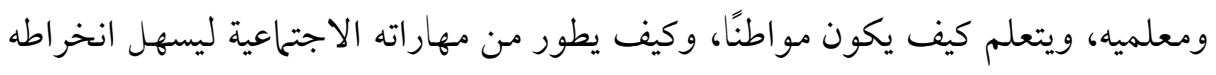
وتفاعله الاجتماعي ومشاركته كمواطن. وهذا التحدي - بصفة خاصة - يعظم من محورية

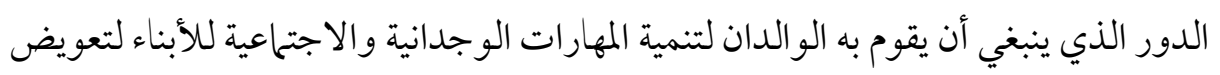
ما ينقصهم في هذا الجانب بغيابهم عن مدارسهم.

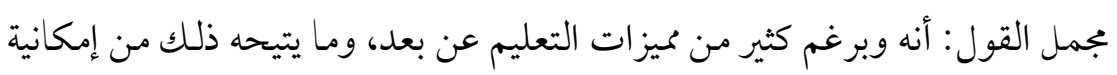

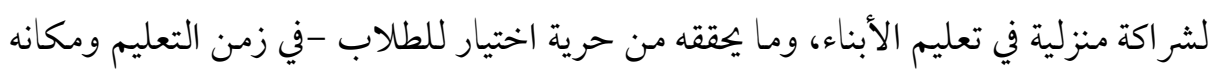

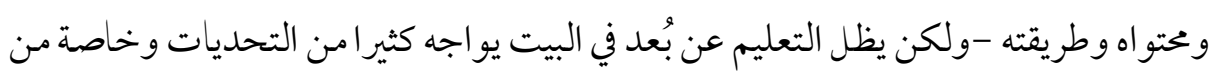
وجهة نظر المعلمين وأولياء الأمور. ه- أهم فرص تعظيم الدور التربوي/ التعليمي للبيت العربي في زمن الجائحة. http://dx.doi.org/10.29009/ijres.3.4.1 
فحين نتوسل بأسلوب التحليل البيئي SWOT لواقع التعليم العربي المتاح في زمن

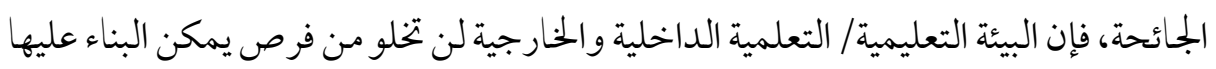
واستثمارها لتعظيم الدور التعليمي/ التعلمي للبيت، ومن ثم تعظيم نو اتج الشراكة التعليمية التعلمية بين المدرسة والبيت. وقد عرضت الورقة في المحور السابق لأهم التحديات (المخاطر) ونقاط الضعف في البيئتين الداخلية والخارجية التي تواجه التعليم الإلكتروني عن بُعد، ومن ثم تحد من فئس فاعلية

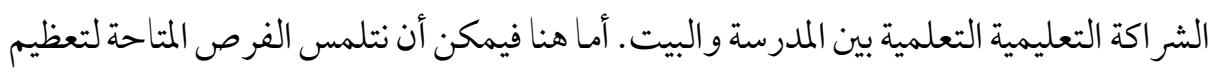
إيجابيات التعليم الإلكتروني عن بعد، ومن ثم تحديد الفرص التي يمكن أن تعزز الشراكة بين المدرسة والبيت في زمن كورونا. تعبر إحدى معلمات اللغة الانجليزية بإحدى المدارس الدولية بمصر عن بعض هذه

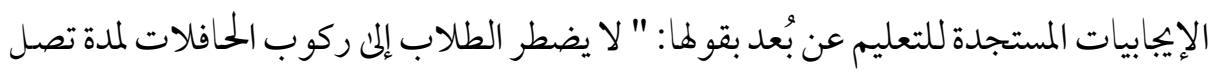

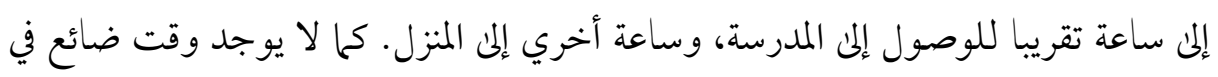

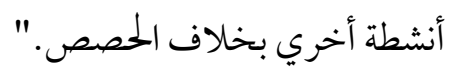
وأضافت ":الاعتماد علن النفس من أهم مقومات نجاح عملية التعليم والتعلم عن بُعد،

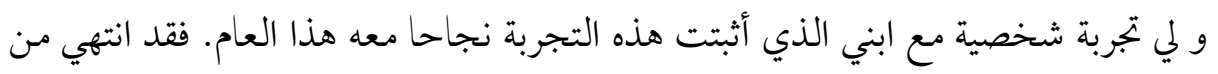

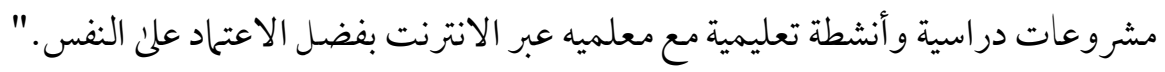

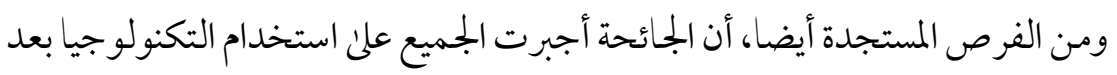
أن ألغنى فيروس كورونا فكرة التعلم في قاعات الدراسة التقليدية، فلم يعد التعلم عن بُعد يقتصر علن فئات بعينها، إذ الجميع في منظومة التعليم يستخدمون التطبيقات الإلكترونية

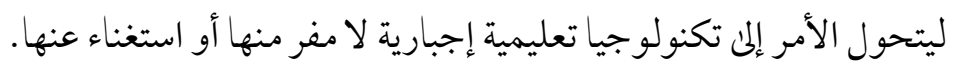


ويؤدي استخدام تطبيقات التكنولوجيا والإنترنت في التعليم إلى إثراء العملية التعليمية من خلال توفير خيار ات المو اد التعليمية المقروءة والمسموعة والمرئية كأن يطلب من الدارسين البحث في جوجل Google عن معلومات ذات صلة بموضوع الدراسة أو مشاهدة فيديو على YOUTUBE ويعبر بعض الطلاب عن إيمابيات أخرى للتعليم عن بعد وهم في البيت وخاصة في ظروف الجائحة، إذ يتيح لهم التعلم في البيت حرية حركة أكثر مثل فرص غسيل الأيدي و التحرر من قيود وضو ابط حجرة الدراسة وتعليمات المعلمين، كما يتيح خيارات أكثر لاختيار زمن التعلم والاحتفاظ بالمادة المعلمة من خلال حفظها، تخزينها واستر جاعها متحى شاء. ومن الفرص و الإيجابيات المستجدة للتعليم عن بُعد، أن ما فرضته الجمائحة من أوضاع دفعت النظم التعليمية إلى طرح المبادرات الإبداعية النظامية والفردية لتتغلب على صعوبات التعليم الناشئة عن إغلاق المدارس وتعليق الدراسة. فقد ظهرت الكثير من المبادرات الحاصة بمنصات التعليم الإلكتروني عن بُعد، والشر اكات الجديدة بين وزارات التعليم والوزارات الأخرى كوزارة الاتصالات. كذلك استحدثت تطبيقات جديدة للاختبارات ونظم التقويم، وتطبيقات جديدة في نظم الإدارة الإلكترونية والتدريب الإلكتروني عن بُعد، والمؤتمرات واللقاءات والاجتماعات الدورية من خلال تطبيقات الإدارة الإلكترونية في التعليم. 7 - متطلبات جسر الفجوة بين المدرسة والبيت لتحقيق شر اكة تعليمية فاعلة. وعود علن بدء، تعود الورقة إلى إعادة التأكيد علن ما سبق طرحه في مقدمتها، وهو أن كل شيء في زمن الجائحة قد تغير، و"التعليم" لريكن استثناءً، لأن التعليم يمس، بل ويتداخل ويتشابك مع كل ما تغير في ظل الجائحة من سياسة واقتصاد وإعلام وتكنولوجيا وغذاء ودواء وصحة ومرض ومواصلات و اتصالات بدرجة يصعب، بل يستحيل معها، أن يو اجه التعليم المستجدات بنفس الأساليب التقليدية التي كانت قائمة قبل الجلائحة. ولأن الرهان على التعليم 
أكثر من سواه في حركة "التغيير" في المجتمع، فإنه - أي التعليم - يجب أن يتغير حتى يكون أقدر علن توجيه حركة التغيير ومساراتها، لا أن يكون "ضحية" للتغيير.

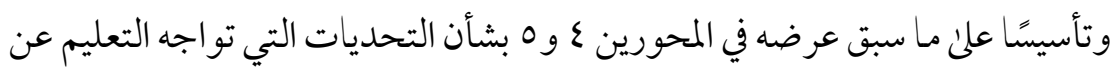
بعد، ومن ثم تضعف من الدور التعليمي المتوقع للبيت، والفرص القائمة والمستجدة في البيئة الخارجية للنظام التعليمي. - مني. و انطلاقامن "الفرضية النظرية "الني انطلقت منها هذه الورقة ،والتي تعظم من الدور

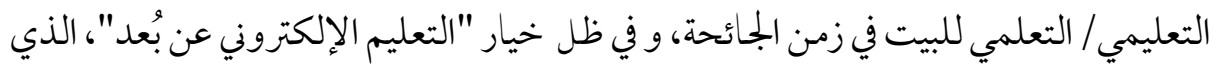

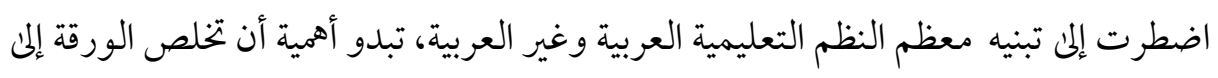
بلورة أهم المتطلبات التي ينبغي للأنظمة التعليمية توفيرها والوفاء بها، حتى يمكن استثمار الإيجابيات والفرص "القائمة" و "المتوقعة" لتجسير الفجوة بين المدرسة والبيت تربويًا وتعليميًا، ومن ثم تعظيم Maximizing فرص الشراكة الفاعلة بين المدرسة والبيت، وتبدو أهم هذه المتطلبات فيها يأتي: 1/ 1 : متطلبات سياسية الدعم السياسي لوزارة التعليم والتعليم العالي في مبادراتها في مواجهة الآثار الناتجة عن إغلاق المدارس والجامعات باعتبار التعليم قضية أمن قومي ومن ثم ضرورة توفر الإرادة

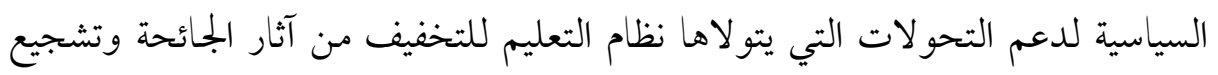
الشراكة بين التعليم وخختلف أنظمة المجتمع وكياناته المجتمعية كمنظمات المجتمع المدني

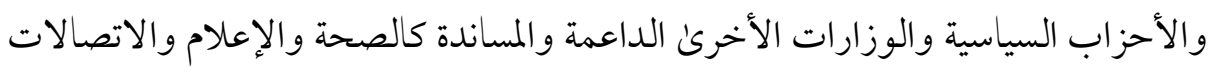
والمو اصلات والداخلية ..إلخ. 


\section{T/ Y / / متطلبات تشريعية وقانونية}

سن التشريعات الدستورية والقانونية التي تسمح بحرية الحركة للقيادات التعليمية

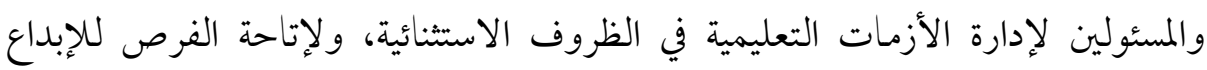

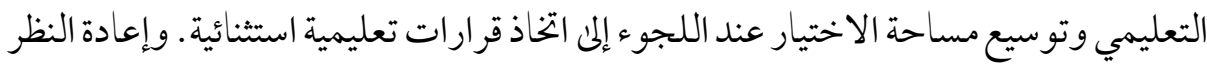
في القوانين والضوابط التعليمية بشأن سياسات التعليم وإجراءاته وتنظيم الدراسة والجدول

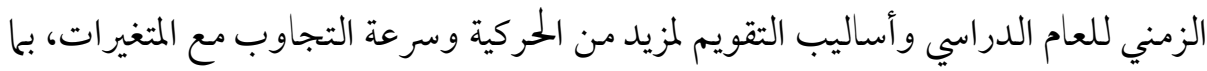
يحافظ علن الفرص التعليمية للتلاميذ والطلاب. كذلك وضع بعض الضو ابط ونس والمحددات القانونية التي تسمح لإدارات التعليم بتخفيف حدة الفوارق الطبقية والجغرافية، الناتجة عن تباين فرص التلاميذ وإمكانتهم في التعليم عن بعد، كتشريعات محاربة الدروس الخصوصية بحسية داخل المنازل لمواجهة تعميق الفوارق الطبقية بين الأسر، ونقل التفاوت الطبقي من المدارس إلى تلى

$$
\text { المنازل بشكل أكثر ضررًا. }
$$

\section{r/ r ب: متطلبات اقتصادية وتمويلية}

زيادة موازنات التعليم في الموازنة العامة للدولة ليسمح بتوفير السيولة المالية التي يمتاجها التعليم عند اللجوء للتحول الرقمي والتعليم عن بُعد، وتعلم التلاميذ في بيوتهم.

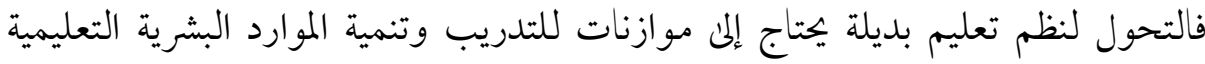
والحو افز والمكافآت التي تجعلها تعمل بححاس في ظروف التحول . كما يحتاج إلى دعم تمويلي

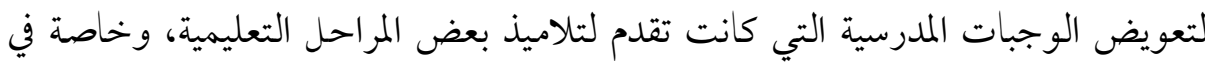

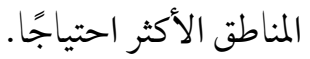


ومن أهمها، استحداث إدارات للتعليم عن بعد بالمديريات والإدارات التعليمية و المدارس، وكذا استحداث تنظيمات إدارية وتربوية جديدة للتنسيق بين المدارس والمنازل في تعليم الأبناء في هذه الظروف الاستثائية. ويمكن اختيار هذه التنظيمات وتلك اللجان من بجالس الأمناء والآباء و المعلمين بالمدارس لتكون مهمة هذه التنظيات توفير الدعم للتعليم عن بُعد، وتطوير الشراكة بين المدارس والمنازل في تعليم وتعلم الأبناء. كما تكون مهمة هذه التنظيمات نشر "ثقافة الثقة" فيما تتخذه المدارس من إجراءات ودعم حماس التلاميذ والطلاب للتعلم في البيت. فالمدارس لا تستطيع أن تو اجه هذه الظروف الاستثنئية وتبدع إداريًا وتعليميًا دون مؤازرة ودعم من ظهيرها الاجتماعي المحلي، وخاصة أولياء الأمور الذين يتواجدون مع أبنائهم (التلاميذ و الطلاب) لفترات زمنية أطول عن مرحلة ما قبل الجائحة في ضوء سياسة وضو ابط "البقاء بالبيت "Stay Home التي أصبحت خيارا عالميًا طوعيًا.

\section{7/ 0 0: متطلبات تربوية/ تعليمية}

إتاحة برامج التنمية المهنية المستدامة للأطقم التعليمية بالمدارس والإدارات التعليمية، ولاسيما المعنية بتطوير المهارات الرقمية للمعلمين والإداريين الخاصة بالتعليم عن بُعد، ومتابعة تعلم التلاميذ، وعمليات تقويم تعلمهم و إدارة الامتحانات، وتدريب الأخصائيين الاجتماعيين و التقنيين، وأخصائي الإعلام التربوي وغيرهم على تفعيل سبل التو اصل مع التلاميذ والطلاب في منازلهم لدعم تعليمهم وتعلمهم وإزالة أية عقبات تواجهـم وتحد من استجاباتهم التعلمية.

\section{7/ آ آ متطلبات تكنولوجية}

تو فير بنية تحتية تقنية من خدمات انترنت وشبكات وكو ادر تقنية بشرية، وكذلك تسهيل دخول التلاميذ والطلاب علن الانترنت مجانيا بتسهيلات تيسر عليهم ذلك. وضرورة توفير الدعم التقني اللوجستي للمدارس والمنازل، وتأسيس المنصات الرقمية التي يدخل عليها 
المتعلمون بمرونة ويسر • وضرورة توفير مر اكز اتصال تقني تتيح للتلاميذ التو اصل معها عند مو اجهتهم لمشكلات أو عقبات. وكذلك تبدو أهمية توفير البرامسج التدريبية والمنح من وزارة الاتصالات والمراكز التقنية القومية للمعلمين المشاركين في برامج التعليم عن بُعد. ولا يقل عن ذلك أهمية مضاعفة إمكانات الإتاحة التكنولوجية للتلاميذ والطلاب، بإعفائهم من تكلفة الدخول علن المنصات الرقمية للتعلم عن بُعد، وتسهيل امتلاك الأجهزة والحو اسيب اللوحية الصغيرة، وتو فير الدروس والشروح التوضيحية لتيسير تمكينهم من مهار ات التعلم عن بُعد من

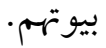

\section{V/T}

توفير بر امج دعم اتصالي و إعلامي للتعليم عن بعد تتاح فيه الفرصة لبث رسائل مو جهة للتلاميذ وأولياء الأمور عبر الإذاعة والتليفزيون ومنتديات الانترنت لتشجيعهم علن التعليم المنزلي والثقة فيها تقدمه المدارس عن بعد للأبناء من أجل تعليمهم. ويمكن لوسائل الاتصال والإعلام بمختلف صورها وأشكاها أن تسهم - بدرجة كبيرة - في بناء ودعم الشراكة بين المدارس والمنازل من خلال اللقاءات الإعلامية مع الخبراء والمختصين و المعلمين والقيادات الشعبية والبرلمانية، وكذا اللقاءات الاستقصائية الخارجية مع التلاميذ والطلاب للوقوف على ما يواجهونه من مشكلات أولاً بأول. ويرتبط بهذه المتطلبات كذلك، ضرورة إتاحة فرص التو اصل الهاتفي و الإلكتروني بين التلاميذ والطلاب ومدارسهم ومعلميهم لدعم الثقة وتجسير الفجوة بين الجهود التعليمية للمدارس عن بعد، والأنشطة التعلمية للمتعلمين في منازلهم عبر

$$
\text { جسور تو اصل ممكنة وميسورة. }
$$

1/ 1 1 متطلبات اجتماعية وأسرية

ولأن التعليم عن بعد مرتبط بالبقاء في البيت Stay Home، فإن ذلك يتيح للمتعلمين

التعلم بين أسرهم وذويهم، وهذا يلقي مسئولية اجتحاعية ووجدانية وتعليمية علن الوالدين فيما 
يتعلق بتوفير الدعم النفسي والوجداني لأبنائهم أثناء تعلمهم وتلقيهم الدروس عن بعد.

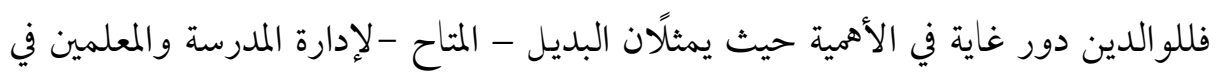

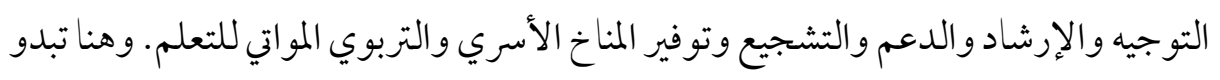

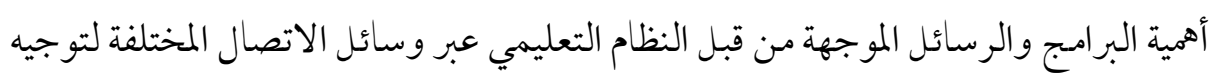
ودعم الو الدين في هذا الاتجاه. 1/ 9/ وتطلبات صحية وغذائية

فثمة متطلبات لابدمن توفرها فيما يتصل بتوفير البيئة التعليمية/ التعلمية الآمنة صحيًا

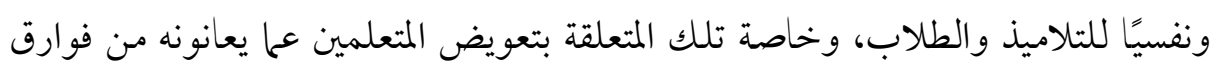
طبقية مع نظر ائهم في الرعاية الصحية والدعم الغذائي. فالتلاميذ والطلاب في المناطق الفقيرة

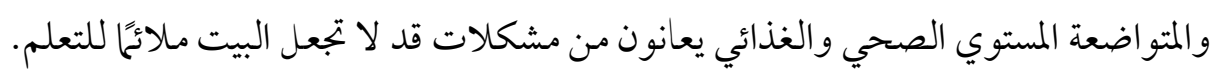

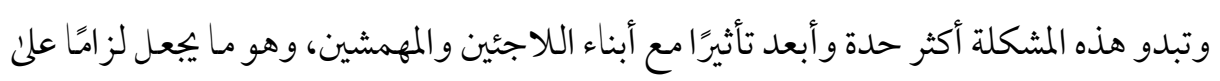
الدولة والنظم التعليمية والصحية ضرورة توفير بدائل للوجبات الغذائية المدرسية مع صغار التلاميذ، والبدائل الممكنة لبرامج الرعاية الصحية المدرسية. أما بعد، ،"،

فتلكم هي أهم المتطلبات التي ير اهاصاحب هذه الورقة مرشحة أكثر من غيرها لتسهيل

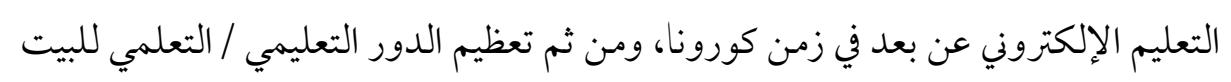

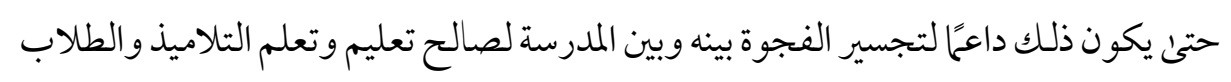

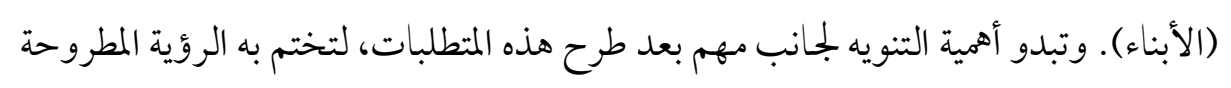

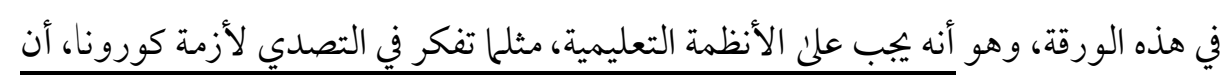
تفكر أيضًا في كيفية الخروج منها وهي أقوي من ذي قبل فيل....ذلك هو التحدي المستقبلي. 


\section{References:}

The United Nations Development Program in the Arab States (response of the Arab countries to the Corona-Covid 19 pandemic) Retrieved on (9/6/2020) from: virus, so what are we going to do? (In Arabic) Retrieved on (6/6/2020) from: Wikipedia: https://ar.wikipedia.org/wiki

World Human -https: //www.un.org/ar/coronavirus/articles/corona-undp-arab-states Development Report 2013 in English on the website:http://hdr.undp.org

Zayed, Hani. (2020). Distance learning “in the face of" the new Corona is available at https://www.scientificamerican.com/arabic/articles/news/distance-learningversus-covid19/ 
